\title{
Assessing Initial Response to High-Frequency Jet Ventilation in Premature Infants With Hypercapnic Respiratory Failure
}

\author{
Craig R Wheeler RRT-NPS, Craig D Smallwood RRT, Iris O'Donnell RRT-NPS, \\ Daniel Gagner RRT-NPS, and Martha C Sola-Visner MD
}

\begin{abstract}
BACKGROUND: High-frequency jet ventilation (HFJV) has been used in conjunction with conventional ventilation for infants with respiratory failure. We sought to identify parameters that were associated with successful application of $\mathrm{HFJV}$ in patients with hypercapnic respiratory failure. METHODS: A single-center, retrospective review of infants who received HFJV was conducted. Subjects were enrolled if birthweight was $\leq 2,000 \mathrm{~g}$ and capillary $\mathbf{P}_{\mathrm{CO}_{2}}$ was $\geq 55 \mathrm{~mm} \mathrm{Hg}$. Ventilator parameters and physiologic data were recorded at $1 \mathrm{~h}$ before HFJV initiation and at hours 1, 4, and 6 following conversion. Subjects were classified as responders if capillary $\mathbf{P}_{\mathrm{CO}_{2}}$ was reduced by $\geq 10 \%$ after $1 \mathrm{~h}$ of HFJV. Data included peak inspiratory pressure, PEEP, capillary $\mathrm{P}_{\mathrm{CO}}$, and oxygen saturation index (equal to mean airway pressure $\times \mathrm{F}_{\mathrm{IO}_{2}} \times 100 / \mathrm{S}_{\mathrm{pO}_{2}}$ ). Because the data were not normally distributed, they are reported as median (interquartile range), and the Mann-Whitney test was used to assess differences in continuous data between groups. Categorical data were analyzed using a chi-square and Fisher exact test. RESULTS: Thirty-four premature infants $(n=24$ male) were studied. Twenty-five subjects were classified as responders and demonstrated a significant reduction of capillary $\mathrm{P}_{\mathrm{CO}_{2}}$ and $\mathrm{F}_{\mathrm{IO}_{2}}$ and increased pH within the first hour. The non-responders demonstrated a higher conventional ventilation peak inspiratory pressure (25 $\mathrm{cm}_{2} \mathrm{O}$ vs $19 \mathrm{~cm} \mathrm{H}_{2} \mathrm{O}, P=.005$ ) and had a greater postmenstrual age (30 weeks vs 26.5 weeks, $P=.01)$. This group had a higher oxygen saturation index $(7.25$ vs $3.36, P=.03)$ and $\mathrm{F}_{\mathrm{IO}_{2}}$ requirements $(0.6$ vs $0.35, P=.038)$ at $4 \mathrm{~h}$. CONCLUSIONS: We identified that lower postmenstrual age, improvements in capillary $\mathrm{P}_{\mathrm{CO}_{2}}$ and $\mathrm{pH}$ at $1 \mathrm{~h}$, and a reduction of $\mathrm{F}_{\mathrm{IO}_{2}}$ were associated with good response to HFJV. These data may help to identify patients who are likely to benefit from HFJV in the neonatal intensive care unit. Key words: respiratory distress syndrome; prematurity; mechanical ventilation; high-frequency jet ventilation; high-frequency oscillatory ventilation; chronic lung disease. [Respir Care 2017;62(7):867-872. () 2017 Daedalus Enterprises]
\end{abstract}

\section{Introduction}

Respiratory distress syndrome (RDS) is the most common etiology of respiratory failure in preterm infants, re-

\footnotetext{
Mr Wheeler, Mr Smallwood, Ms O’Donnell, and Mr Gagner are affiliated with Department of Respiratory Care, Boston Children's Hospital, Boston, Massachusetts. Mr Smallwood is also affiliated with the Division of Critical Care Medicine, Department of Anesthesia, Preoperative and Pain Medicine, Boston Children's Hospital and Harvard Medical School, Boston, Massachusetts. Dr Sola-Visner is affiliated with the Division of Newborn Medicine, Boston Children's Hospital and Harvard Medical School, Boston, Massachusetts.
}

The authors have disclosed no conflicts of interest. sulting from surfactant deficiency and associated with lower gestational age. ${ }^{1}$ Whereas the specific etiologies of respiratory failure in premature infants may be multifactorial, it remains a principle indication for mechanical ventilation. Although mechanical ventilation is a lifesaving modality,

\footnotetext{
Mr Wheeler presented a version of this paper as an Editors' Choice abstract at the Open Forum of the American Association for Respiratory Care 62nd International Respiratory Convention and Exhibition, held October 15-18, 2016, in San Antonio, Texas.

Correspondence: Craig Wheeler RRT-NPS, Department of Respiratory Care, Boston Children's Hospital, Boston, MA 02115.
}

DOI: $10.4187 /$ respcare.05264 
chronic lung injury and subsequent bronchopulmonary dysplasia are associated complications, and therefore, strategies to mitigate these effects are desirable. ${ }^{2}$

See the Related Editorial on Page 997

High-frequency ventilation is a form of mechanical ventilation that utilizes rapid breathing frequencies (240900 breaths/min), and delivers small tidal volumes $\left(\mathrm{V}_{\mathrm{T}}\right)$ that can be smaller than anatomic dead space. ${ }^{3}$ The most commonly used modes of high-frequency ventilation in the United States include high-frequency oscillatory ventilation (HFOV) and high-frequency jet ventilation (HFJV). Both modes have been used clinically for $>30$ years and are considered standard alternatives for infants with refractory respiratory failure while receiving conventional mechanical ventilation. Although systematic reviews have reported no improved benefit in outcomes data for the elective use of either HFOV or HFJV in infants with RDS when compared with conventional ventilation, many clinicians reserve these modalities for rescue use. ${ }^{4-7}$ Several of the trials included within these reviews and other studies looking at rescue use were conducted decades ago, before the availability of surfactant replacement therapy and routine use of antenatal steroids. ${ }^{8-10}$ Furthermore, there are no large studies comparing HFOV directly with HFJV, and HFJV research is far less robust; therefore, the decision to use one mode over another is often left to clinical judgment. There are also limited data on treatment guiding the clinician to decide whether a patient has positively or negatively responded to HFJV. Therefore, we sought to identify parameters that are associated with successful application of HFJV in subjects with hypercapnic respiratory failure refractory to conventional ventilation or HFOV. We hypothesized that differences in measurable physiologic parameters would be observed between subjects who initially "responded," when compared with those subjects who did not.

\section{Methods}

\section{Subjects}

All subjects were outborn and were transferred to the Boston Children's Hospital neonatal ICU for further medical or surgical management. An institutional review board approved (P00021911) retrospective analysis of subjects admitted to the neonatal ICU who underwent HFJV between January 2012 and January 2016. Subjects were included in the study if birthweight was $\leq 2,000 \mathrm{~g}$ and capillary partial pressure of carbon dioxide (capillary $\mathrm{P}_{\mathrm{CO}_{2}}$ ) was $\geq 55 \mathrm{~mm} \mathrm{Hg}$. The timing of transition to HFJV was left to the discretion of the medical team. Patients were excluded if they had unrepaired complex congenital heart

\section{QUICK LOOK}

\section{Current knowledge}

The use of rescue high-frequency jet ventilation (HFJV) in premature infants with respiratory failure is an accepted standard of care in most neonatal ICUs. There are no established guidelines for the use HFJV as a rescue strategy, and the body of literature on this topic is inconclusive.

\section{What this paper contributes to our knowledge}

In a retrospective review of premature subjects with respiratory failure, HFJV was used as a rescue mode of ventilation. Responders to HFJV were most likely to demonstrate improved $\mathrm{CO}_{2}$ clearance and lower oxygen saturation index within $4 \mathrm{~h}$ following the initiation of HFJV. Subjects who did not initially respond were transitioned from higher conventional ventilation PIP, administered HFJV later, and exhibited higher oxygen saturation index $4 \mathrm{~h}$ following transition.

disease, weighed $>2,000 \mathrm{~g}$, or were placed on HFJV at the time of admission. The primary aims of this study were to elucidate which physiologic parameters could be used to identify a successful response in premature infants who received HFJV as a rescue therapy.

All subjects were ventilated with a Servo-i (Maquet, Camden, New Jersey) in pressure control-intermittent mandatory ventilation mode or HFOV (3100A, BD, Franklin Lakes, New Jersey) before conversion to HFJV (Life Pulse, Bunnell, Salt Lake City, Utah). Equipment was calibrated according to manufacturer specifications before application. All endotracheal tube adapters were exchanged with an adapter (LifePort, Bunnell, Salt Lake City, Utah) of appropriate size to allow for HFJV monitoring and regulation of proximal airway pressures according to manufacturer recommendations. The conventional ventilator was used in tandem with HFJV to provide PEEP, sigh-breaths, bias flow, and an exhalation valve, as specified by manufacturer recommendations.

Subjects were converted to HFJV in accordance with institutional guidelines using a peak inspiratory pressure (HFJV PIP) of $3-5 \mathrm{~cm} \mathrm{H}_{2} \mathrm{O}$ above the set PIP while receiving conventional ventilation, frequency of $420(7 \mathrm{~Hz})$, and a jet valve on-time of $20 \mathrm{~ms}$. PEEP was increased by $1-2 \mathrm{~cm} \mathrm{H}_{2} \mathrm{O}$, to maintain the same mean airway pressure $\left(\overline{\mathrm{P}}_{\mathrm{aw}}\right)$ preceding the transition to HFJV. In subjects transitioned from HFOV, PEEP was initially titrated to attain a similar $\overline{\mathrm{P}}_{\mathrm{aw}}$ as HFOV. HFJV PIP was primarily adjusted to maintain a $\mathrm{pH}$ of $\geq 7.25$ and capillary $\mathrm{P}_{\mathrm{CO}_{2}}$ between 50 and $60 \mathrm{~mm} \mathrm{Hg}$. $\mathrm{F}_{\mathrm{IO}_{2}}$ was titrated to maintain $\mathrm{S}_{\mathrm{pO}_{2}}$ between 88 and $96 \%$. If $\mathrm{F}_{\mathrm{IO}_{2}}$ could not be weaned below 0.6 , PEEP was increased in $1-2 \mathrm{~cm} \mathrm{H}_{2} \mathrm{O}$ increments until this target had been met. 
Table 1. Subject Demographics

\begin{tabular}{|c|c|c|c|}
\hline Characteristics & Responders $(n=25)$ & Non-Responders $(n=9)$ & $P$ \\
\hline Male/female sex, $n$ & $16 / 9$ & $8 / 1$ & .23 \\
\hline PMA, median (IQR) weeks & $26.5(25-28)$ & $30(26.6-31.9)$ & .01 \\
\hline Gestational age, median (IQR) weeks & $24.7(23-25.9)$ & $27(25.5-29.5)$ & .02 \\
\hline Weight, median (IQR) g & $700(600-670)$ & $1,000(670-1650)$ & .058 \\
\hline Ventilator duration before HFJV, median (IQR) h & $23(10-59)$ & $18(3-219)$ & .68 \\
\hline Duration of HFJV, median (IQR) h & $78(46-196)$ & $71(10-145)$ & .29 \\
\hline Received antenatal steroids, $n(\%)$ & $13(52)$ & $7(78)$ & .25 \\
\hline Surfactant administered, $n(\%)$ & $21(84)$ & $9(100)$ & .40 \\
\hline \multicolumn{4}{|l|}{ Reason for admission, $n(\%)$} \\
\hline RDS & $21(84)$ & $9(100)$ & .55 \\
\hline Respiratory failure & $4(16)$ & 0 & .55 \\
\hline \multicolumn{4}{|l|}{ Secondary diagnosis, $n(\%)$} \\
\hline Necrotizing entercolitis & $5(20)$ & $2(22)$ & $>.99$ \\
\hline PDA & $5(20)$ & $2(22)$ & $>.99$ \\
\hline \multicolumn{4}{|l|}{ Ventilator mode before HFJV, $n(\%)$} \\
\hline PC-SIMV & $18(72)$ & $7(78)$ & $>.99$ \\
\hline HFOV & $7(28)$ & $2(22)$ & $>.99$ \\
\hline \multicolumn{4}{|l|}{ Outcome, $n(\%)$} \\
\hline Survived to discharge & $18(72)$ & $8(88)$ & .40 \\
\hline $\begin{array}{l}\text { PMA = postmenstrual age } \\
\text { IQR = interquartile range } \\
\text { HFJV = high-frequency jet ventilation } \\
\text { RDS = respiratory distress syndrome } \\
\text { PDA = patient ductus arteriosus } \\
\text { PC-SIMV = pressure control-synchronized intermittent mandatory } \\
\text { HFOV = high-frequency oscillatory ventilation }\end{array}$ & & & \\
\hline
\end{tabular}

Demographic information, along with ventilator, physiologic, and laboratory data were collected. Data included PIP, PEEP, $\overline{\mathrm{P}}_{\mathrm{aw}}$, capillary $\mathrm{P}_{\mathrm{CO}_{2}}$, and oxygen saturation in$\operatorname{dex}\left(\mathrm{OSI}=\right.$ mean airway pressure $\left.\times \mathrm{F}_{\mathrm{IO}_{2}} \times 100 / \mathrm{S}_{\mathrm{pO}_{2}}\right)$. Ventilator parameters and physiologic data were extracted from the electronic medical record and analyzed at $1 \mathrm{~h}$ before HFJV and at hours 1, 4, and 6 following conversion. Capillary $\mathrm{P}_{\mathrm{CO}_{2}}$ and $\mathrm{pH}$ were included for analysis. provided that values were collected 45 min before or after each time interval. Laboratory data that were missing or did not correspond with these intervals or were omitted.

Subjects were classified as responders if capillary $\mathrm{P}_{\mathrm{CO}_{2}}$ was reduced by $\geq 10 \%$ at $1 \mathrm{~h}$ of HFJV. This threshold was decided a priori and was comparable with statistically significant reductions in $\mathrm{P}_{\mathrm{aCO}}$ observed during a randomized trial of HFJV versus conventional ventilation. ${ }^{11}$ The cohort was then divided into responder and non-responder categories, respectively, and transcribed into Excel 15.24 (Microsoft Corp, Redmond, Washington) spreadsheets. Prism 6.0 (GraphPad Software, La Jolla, California) was used to analyze all data. Since the data were not normally distributed, they are reported as median (interquartile range). Mann-Whitney unpaired $t$ test was used to assess differences in continuous variables, and the chi-square and Fisher exact test were used for categorical variables between the groups. Friedman tests were used to detect whether there were significant changes in OSI within groups using the baseline values as a referent. Post hoc analysis was conducted using the Dunn test. All tests were 2-sided, and differences of $<.05$ were considered significant. Plavka et $\mathrm{al}^{12}$ have previously reported mean $\pm \mathrm{SD} \mathrm{CO}_{2}$ values of $61.5 \pm 10.3 \mathrm{~mm} \mathrm{Hg}$ in premature infants preceding HFJV. A power analysis indicated that a total sample of 16 subjects would be required to detect a $10 \%$ change in $\mathrm{CO}_{2}$ with $80 \%$ power $(1-\beta)$, using a $t$ test with an $\alpha$ of .05 .

\section{Results}

Thirty-four premature subjects ( $n=24$ male) were studied. Before conversion to HFJV, the median $\mathrm{V}_{\mathrm{T}}$ was $7 \mathrm{~mL} / \mathrm{kg}$ $(6-7.7 \mathrm{~mL} / \mathrm{kg})$ and a set frequency of 40 breaths $/ \mathrm{min}(38-$ 45 breaths $/ \mathrm{min}$ ) receiving conventional ventilation. Thirty subjects were categorized as RDS based upon age, history of at least one dose of exogenous surfactant, and radiographic documentation of surfactant deficiency. Four subjects were admitted with other diagnoses (congenital pulmonary airway malformation, omphalocele, and two with complete heart block) and were classified as respiratory failure. The median postmenstrual age was 26.6 weeks (25-28 weeks) in the responder group and 30 weeks (26.6-31 weeks) in non-responders $(P=.01)$ at the time HFJV was initiated. Overall survival to discharge was $76 \%$ 
with no statistical difference observed between groups. Demographic data and subject characteristics are displayed in Table 1. In total, 9 subjects $(26 \%)$ were transitioned from HFOV to HFJV. These subjects were all on an HFOV frequency of $15 \mathrm{~Hz}, \overline{\mathrm{P}}_{\mathrm{aw}}$ of $11 \mathrm{~cm} \mathrm{H}_{2} \mathrm{O}\left(9-12.5 \mathrm{~cm} \mathrm{H}_{2} \mathrm{O}\right)$, and median pressure amplitude of $28 \mathrm{~cm} \mathrm{H}_{2} \mathrm{O}$ (23$40 \mathrm{~cm} \mathrm{H}_{2} \mathrm{O}$ ). Twenty-five subjects were classified as responders and demonstrated a reduction of capillary $\mathrm{P}_{\mathrm{CO}_{2}}$, $\mathrm{F}_{\mathrm{IO}_{2}}$ and increased $\mathrm{pH}$ within the first hour, and 9 subjects were classified as non-responders. The non-responder group was transitioned to HFJV from a higher conventional ventilation $\mathrm{PIP}\left(25 \mathrm{~cm} \mathrm{H}_{2} \mathrm{O}\right.$ vs $\left.19 \mathrm{~cm} \mathrm{H}_{2} \mathrm{O}, P=.005\right)$ and a later postmenstrual age (30 weeks vs 26.5 weeks, $P=.01)$ than their counterparts. The non-responders also demonstrated significantly higher OSI (7.25 vs 3.36, $P=.03$ ) values and $\mathrm{F}_{\mathrm{IO}_{2}}$ requirements $(0.6$ vs 0.35 , $P=.038)$ at $4 \mathrm{~h}$. Capillary $\mathrm{P}_{\mathrm{CO}_{2}}$ and $\mathrm{pH}$ preceding and $1 \mathrm{~h}$ following transition to HFJV were complete $(n=34)$. However, fewer blood gases were drawn at the 4-h $(n=29)$ and 6-h $(n=24)$ time frames. Ventilator parameters and physiologic data are displayed in Table 2 . The Friedman test detected a statistically significant difference in OSI progression within the responder group, which was not present in the non-responder group $(P=.037$ and $P=.94$, respectively). Dunn's multiple comparisons post-test identified lower OSI values existing at both hours 4 and 6 in the responder group $(P<.05)$, when compared with referent (baseline).

\section{Discussion}

Subjects who demonstrated a positive response to HFJV were characterized by improved $\mathrm{pH}$, lower capillary $\mathrm{P}_{\mathrm{CO}}$, and stabilization of ventilator parameters after $1 \mathrm{~h}$. Non-responders exhibited worsening oxygenation deficits at $4 \mathrm{~h}$ and may have potentially benefited from further increases in PEEP.

HFJV has been associated with improvements in $\mathrm{CO}_{2}$ elimination and subsequently increased arterial $\mathrm{pH}$ following rescue use in premature and term infants. ${ }^{13-15}$ In the current study, capillary $\mathrm{P}_{\mathrm{CO}_{2}}$ and $\mathrm{pH}$ were studied considering that the majority of subjects $(n=29,85 \%)$ did not have arterial access when HFJV was initiated. A significant reduction in capillary $\mathrm{P}_{\mathrm{CO}_{2}}$ and elevation of $\mathrm{pH}$ were observed in the responder group following $1 \mathrm{~h}$ of HFJV. These subjects were also noted to have significantly lower conventional ventilation peak inspiratory pressures before HFJV conversion. In the responder group, capillary $\mathrm{P}_{\mathrm{CO}_{2}}$ and $\mathrm{pH}$ remained within targeted clinical range without significant escalation in ventilator support at hours 4 and 6. Two subjects in the non-responder group had persistent hypercapnia and hypoxia despite nearly maximal settings and were transitioned back to conventional ventilation and HFOV at 5 and $6 \mathrm{~h}$, respectively.

OSI was a secondary outcome observed between cohorts to assess the severity of hypoxic respiratory failure
Table 2. Ventilator and Physiologic Data

\begin{tabular}{|c|c|c|c|}
\hline Parameter & Responders & Non-Responders & $P$ \\
\hline \multicolumn{4}{|l|}{ Pre-HFJV } \\
\hline $\begin{array}{l}\text { Conventional mechanical } \\
\text { ventilation PIP, } \mathrm{cm} \mathrm{H}_{2} \mathrm{O}\end{array}$ & $19(17.5-21)$ & $25(23-25)$ & .005 \\
\hline PEEP, $\mathrm{cm} \mathrm{H}_{2} \mathrm{O}$ & $5(5-6)$ & $6(5-7)$ & .15 \\
\hline$\overline{\mathrm{P}}_{\mathrm{aw}}, \mathrm{cm} \mathrm{H}_{2} \mathrm{O}$ & $10(9-11)$ & $10(8-11.5)$ & .47 \\
\hline Capillary $\mathrm{P}_{\mathrm{CO}_{2}}, \mathrm{~mm} \mathrm{Hg}$ & $72(63-90)$ & $71(61-93)$ & .80 \\
\hline OSI & $5.08(3.45-7.22)$ & $6.98(5.18-8)$ & .13 \\
\hline $\mathrm{F}_{\mathrm{IO}_{2}}$ & $0.5(0.35-0.7)$ & $0.6(0.52-0.88)$ & .16 \\
\hline $\mathrm{pH}$ & $7.10(6.98-7.16)$ & $7.14(7.06-7.24)$ & .22 \\
\hline \multicolumn{4}{|l|}{ HFJV hour 1} \\
\hline HFJV PIP, $\mathrm{cm} \mathrm{H}_{2} \mathrm{O}$ & $25(22.5-31)$ & $26(19.5-33)$ & .95 \\
\hline PEEP, $\mathrm{cm} \mathrm{H}_{2} \mathrm{O}$ & $7(6-8)$ & $7(6-9)$ & .77 \\
\hline 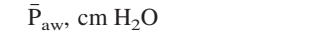 & $10(8.5-9.5)$ & $11(9.5-13.5)$ & .25 \\
\hline Capillary $\mathrm{P}_{\mathrm{CO}_{2}}, \mathrm{~mm} \mathrm{Hg}$ & $49(42-57.5)$ & $87(66.5-100)$ & $<.001$ \\
\hline OSI & $4(2.49-9.51)$ & $6.9(5.43-8.93)$ & .22 \\
\hline $\mathrm{F}_{\mathrm{IO}_{2}}$ & $0.4(0.3-0.52)$ & $0.6(0.45-0.8)$ & .02 \\
\hline $\mathrm{pH}$ & $7.24(7.18-7.31)$ & $7.11(7.05-7.26)$ & .031 \\
\hline \multicolumn{4}{|l|}{ HFJV hour 4} \\
\hline HFJV PIP, $\mathrm{cm} \mathrm{H}_{2} \mathrm{O}$ & $25.5(23-31.5)$ & $31(23.5-38)$ & .29 \\
\hline $\mathrm{PEEP}, \mathrm{cm} \mathrm{H} \mathrm{H}_{2} \mathrm{O}$ & $8(6-9)$ & $8(6-9.5)$ & .74 \\
\hline 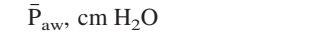 & $10(8.3-11)$ & $12(9-14)$ & .11 \\
\hline Capillary $\mathrm{P}_{\mathrm{CO}_{2}}, \mathrm{~mm} \mathrm{Hg}$ & $47(43.5-57.5)$ & $52(37-109)$ & .73 \\
\hline OSI & $3.36(2.62-5.95)$ & $7.25(4.09-9.72)$ & .03 \\
\hline $\mathrm{F}_{\mathrm{IO}_{2}}$ & $0.35(0.29-0.5)$ & $0.6(0.42-0.8)$ & .038 \\
\hline $\mathrm{pH}^{2}$ & $7.25(7.18-7.28)$ & $7.23(7.10-7.32)$ & .82 \\
\hline \multicolumn{4}{|l|}{ HFJV hour 6} \\
\hline HFJV PIP, $\mathrm{cm} \mathrm{H}_{2} \mathrm{O}$ & $26(22.3-30)$ & $28(20-32)$ & .74 \\
\hline $\mathrm{PEEP}, \mathrm{cm} \mathrm{H} \mathrm{H}_{2} \mathrm{O}$ & $8(6-8.8)$ & $7(6-9)$ & .86 \\
\hline$\overline{\mathrm{P}}_{\mathrm{aw}}, \mathrm{cm} \mathrm{H}_{2} \mathrm{O}$ & $10(8-11)$ & $11.5(8.5-13.5)$ & .23 \\
\hline Capillary $\mathrm{P}_{\mathrm{CO}_{2}}, \mathrm{~mm} \mathrm{Hg}$ & $46(38-58)$ & $61(36-67.5)$ & .38 \\
\hline OSI & $3.62(2.58-6.28)$ & $5.55(4.34-10.26)$ & .12 \\
\hline $\mathrm{F}_{\mathrm{IO}_{2}}$ & $0.37(0.26-0.5)$ & $0.5(0.35-0.65)$ & .22 \\
\hline $\mathrm{pH}$ & $7.26(7.2-7.32)$ & $7.24(7.19-7.29)$ & .65 \\
\hline $\begin{array}{l}\text { Results are median (interquartile rar } \\
\mathrm{HFJV}=\text { high-frequency jet ventilati } \\
\mathrm{PIP}=\text { peak inspiratory pressure } \\
\overline{\mathrm{P}}_{\text {aw }}=\text { mean airway pressure } \\
\text { Capillary } \mathrm{P}_{\mathrm{CO}_{2}}=\text { capillary partial p} \\
\mathrm{OSI}=\text { oxygen saturation index }\end{array}$ & ssure of carbon dioxid & & \\
\hline
\end{tabular}

as described by Rawat et al. ${ }^{16}$ OSI was similar between groups before and $1 \mathrm{~h}$ after conversion to HFJV and was significantly higher in non-responders at hour 4. Additionally, $\mathrm{F}_{\mathrm{IO}_{2}}$ was significantly higher for non-responders during this time, at similar ventilating pressures, which may suggest that these subjects may have benefited from increased PEEP. Furthermore, these findings may suggest that subjects failing HFJV had a more significant oxygenation derangement and are in accordance with those of Stewart et al. ${ }^{15}$ These authors found that responders to HFJV were characterized by a decrease in oxygenation index at hour $4(10.7 \pm 5.2)$ compared with $(17.6 \pm 13.4)$ in non-responders, without an increase in $\overline{\mathrm{P}}_{\mathrm{aw}}$. Similarly, Baumgart et $\mathrm{al}^{13}$ reviewed 73 extracorporeal membrane oxygenation-eligible infants of $>34$ weeks gestational age who received HFJV secondary to intractable respiratory failure. These authors found that infants who survived with HFJV alone had significantly lower oxygenation in- 
dex at 1 and $6 \mathrm{~h}$ and identified subjects with RDS as having the most favorable response to HFJV. Although the subjects in the current study were not extracorporeal membrane oxygenation candidates due to size limitation, and neither oxygenation index nor OSI were used for inclusion criteria, our findings suggest that OSI is a useful metric for non-invasively assessing oxygenation status during HFJV. Moreover, failure to improve from an oxygenation or ventilation standpoint by $6 \mathrm{~h}$ of HFJV may prompt clinicians to optimize recruitment or consider alternative treatment strategies.

Extremely premature infants with evolving chronic lung injury are characterized by the development of heterogeneous aeration, structural immaturity of the lung, high airway resistance, and gas trapping, particularly during exhalation. ${ }^{12}$ In the current review, 9 subjects were transitioned to HFJV from HFOV in the setting of persistent respiratory failure. Of these subjects, 7 responded to HFJV with a median $29 \%$ reduction of capillary $\mathrm{P}_{\mathrm{CO}_{2}}$ and $32 \%$ reduction in OSI; 2 subjects with air leak did not respond at hour 1 and then improved by $6 \mathrm{~h}$ of HFJV. It is possible that the longer passive expiratory phase receiving HFJV at $7 \mathrm{~Hz}(123 \mathrm{~ms})$ compared with $\mathrm{HFOV}$ at $15 \mathrm{~Hz}$ (44 ms), may have contributed to improved gas exchange in this subset of subjects. The optimal range of frequencies of either device is dependent on patient size, the underlying disease process, and associated pulmonary time constants. ${ }^{17,18}$ The majority of randomized control trials reported using HFOV frequencies between 10 and $15 \mathrm{~Hz}$ in premature infants with respiratory failure. ${ }^{4}$ Squires et al ${ }^{19}$ describe the utilization of lower HFOV frequencies (5-6 $\mathrm{Hz}$ ) to afford a longer expiratory phase in infants with pulmonary interstitial emphysema and concluded that this strategy may provide some benefit in gas exchange. Reducing HFOV frequency concomitantly increases the inspiratory time, results in larger $\mathrm{V}_{\mathrm{T}}$, and could potentially exacerbate lung injury in infants with low lung compliance. The ability to maintain a short inspiratory time during HFJV while extending expiratory time may be advantageous in premature infants. Similar findings have been reported in a retrospective review of 10 premature infants with chronic lung injury, hyperinflation, and hypoxic respiratory failure refractory to low frequency HFOV. Friedlich et $\mathrm{al}^{20}$ described a reduction in oxygenation index, $\overline{\mathrm{P}}_{\mathrm{aw}}$, and $\mathrm{F}_{\mathrm{IO}_{2}}$ within $3 \mathrm{~h}$ of HFJV initiation. These authors speculated that HFOV may have contributed to gas trapping by a mechanism of dynamic airway collapse resulting from the active exhalation and fixed 1:2 inspiratory-expiratory ratio. They concluded that passive exhalation, longer expiratory times during HFJV (eg, 1:3.5-1:11.5), and mechanical differences between devices were potentially responsible for improvements in gas exchange. ${ }^{20}$

It is important to mention the limitations of our current study. First, this study was retrospective and therefore re- liant on the accuracy of the medical record. This design introduces the potential for selection bias and is uncontrolled. We attempted to limit selection bias with the aforementioned inclusion and exclusion criteria. Second, our results are reflective of intuition guidelines and suggest that HFJV was a viable strategy in subjects with RDS and persistent hypercapnia refractory to conventional ventilation or HFOV. However, we cannot determine with absolute certainty that subjects improved as a direct result of HFJV, since we did not have a control group of subjects for comparison who continued to receive conventional ventilation or HFOV. Third, capillary $\mathrm{pH}$ and capillary $\mathrm{P}_{\mathrm{CO}_{2}}$ are acceptable alternatives to arterial blood gas samples; capillary oxygenation is not a reliable surrogate for $\mathrm{P}_{\mathrm{aO}}$ value. Therefore, the present investigation utilized $\mathrm{S}_{\mathrm{pO}_{2}}$ and OSI to quantify oxygenation and may not be as accurate as arterial blood gas analysis. However, these metrics have been validated in children. ${ }^{16,21}$ Fourth, long-term follow up was limited due to the nature of the study; therefore, important long-term pulmonary, neurologic, and developmental outcomes were not assessed. Last, we did not utilize severity scoring because many of these systems (eg, newborn respiratory distress scoring system, clinical risk index for babies, and score for neonatal acute physiology) were developed to evaluate the initial risk at time of admission and are limited to the first hours and days of life. ${ }^{22,23}$ Since all patients in our neonatal ICU are postnatally transferred (sometimes days or weeks following birth), we do not utilize these scoring systems. For these reasons, we chose not to include them in our paper.

High-frequency ventilation has been used extensively in addition to other conventional modes of neonatal ventilation. Evidence remains inconclusive; therefore, clinical judgment, institutional preference, and experience generally dictate which mode is used and when. Further research is needed to delineate the optimal modes of ventilation in a context specific to the underlying physiology and disease state. Moreover, prospective randomized control trials are needed to rigorously evaluate differences between high-frequency devices. The current study suggests that HFJV may be more efficacious when initiated earlier and further elaborates on the initial physiologic parameters that may suggest a positive response to HFJV.

\section{Conclusions}

We identified that lower postmenstrual age, reduced PIP while receiving conventional ventilation, reduced $\mathrm{F}_{\mathrm{IO}_{2}}$, reduced capillary $\mathrm{P}_{\mathrm{CO}_{2}}$, and improved $\mathrm{pH}$ during HFJV at $1 \mathrm{~h}$ were associated with a good response to HFJV, without escalation in ventilator settings. The non-responder group demonstrated a concomitant increase in both OSI and $\mathrm{F}_{\mathrm{IO}_{2}}$ with no significant change in ventilator pressures at hour 4 , which may suggest the need to increase PEEP/ $\overline{\mathrm{P}}_{\mathrm{aw}}$. These 
data may lead to early identification of infants who are most likely to benefit from HFJV in the neonatal ICU and may prevent extended application of HFJV in patients who do not demonstrate a benefit within 6 hours.

\section{REFERENCES}

1. Stoll BJ, Hansen NI, Bell EF, Shankaran S, Laptook AR, Walsh MC, et al. Neonatal outcomes of extremely preterm infants from the NICHD Neonatal Research Network. Pediatrics 2010;126(3):443-456.

2. Bhandari A, McGrath-Morrow S. Long-term pulmonary outcomes of patients with bronchopulmonary dysplasia. Semin Perinatol 2013; 37(2):132-137.

3. Lampland AL, Mammel MC. The role of high-frequency ventilation in neonates: evidence-based recommendations. Clin Perinatol 2007; 34(1):129-144, viii.

4. Cools F, Askie LM, Offringa M, Asselin JM, Calvert SA, Courtney $\mathrm{SE}$, et al. Elective high-frequency oscillatory versus conventional ventilation in preterm infants: a systematic review and meta-analysis of individual patients' data. Lancet 2010;375(9731):2082-2091.

5. Cools F, Henderson-Smart DJ, Offringa M, Askie LM. Elective high frequency oscillatory ventilation versus conventional ventilation for acute pulmonary dysfunction in preterm infants. Cochrane Database Syst Rev 2009(3):CD000104.

6. Wiswell TE, Graziani LJ, Kornhauser MS, Cullen J, Merton DA, McKee L, Spitzer AR. High-frequency jet ventilation in the early management of respiratory distress syndrome is associated with a greater risk for adverse outcomes. Pediatrics 1996;98(6 Pt 1):10351043.

7. Keszler M, Modanlou HD, Brudno DS, Clark FI, Cohen RS, Ryan RM, et al. Multicenter controlled clinical trial of high-frequency jet ventilation in preterm infants with uncomplicated respiratory distress syndrome. Pediatrics 1997;100(4):593-599.

8. Rojas-Reyes MX, Orrego-Rojas PA. Rescue high-frequency jet ventilation versus conventional ventilation for severe pulmonary dysfunction in preterm infants. Cochrane Database Syst Rev 2015;(10): CD000437.

9. HiFO Study Group. Randomized study of high-frequency oscillatory ventilation in infants with severe respiratory distress syndrome. J Pediatr 1993;122(4):609-619.

10. Keszler M, Donn SM, Bucciarelli RL, Alverson DC, Hart M, Lunyong $\mathrm{V}$, et al. Multicenter controlled trial comparing high-frequency jet ventilation and conventional mechanical ventilation in newborn infants with pulmonary interstitial emphysema. J Pediatr 1991;119(1 Pt 1):85-93.
11. Carlo WA, Chatburn RL, Martin RJ. Randomized trial of highfrequency jet ventilation versus conventional ventilation in respiratory distress syndrome. J Pediatr 1987;110(2):275-282.

12. Plavka R, Dokoupilová M, Pazderová L, Kopecký P, Sebron V, Zapadlo M, Keszler M. High-frequency jet ventilation improves gas exchange in extremely immature infants with evolving chronic lung disease. Am J Perinatol 2006;23(8):467-472.

13. Baumgart S, Hirschl RB, Butler SZ, Coburn CE, Spitzer AR. Diagnosis-related criteria in the consideration of extracorporeal membrane oxygenation in neonates previously treated with high-frequency jet ventilation. Pediatrics 1992;89(3):491-494.

14. Engle WA, Yoder MC, Andreoli SP, Darragh RK, Langefeld CD, Hui SL. Controlled prospective randomized comparison of highfrequency jet ventilation and conventional ventilation in neonates with respiratory failure and persistent pulmonary hypertension. J Perinatol 1997;17(1):3-9.

15. Stewart DL, Dela Cruz TV, Duncan SD, Cook LN. Response to high frequency jet ventilation may predict the need for extracorporeal membrane oxygenation. Eur Respir J 1996;9(6):1257-1260.

16. Rawat M, Chandrasekharan PK, Williams A, Gugino S, Koenigsknecht C, Swartz D, et al. Oxygen saturation index and severity of hypoxic respiratory failure. Neonatology 2015;107(3):161-166.

17. Pillow JJ. High-frequency oscillatory ventilation: mechanisms of gas exchange and lung mechanics. Crit Care Med 2005;33(3 Suppl): S135-S141.

18. Pillow JJ, Neil H, Wilkinson MH, Ramsden CA. Effect of I/E ratio on mean alveolar pressure during high-frequency oscillatory ventilation. J Appl Physiol 1999;87(1):407-414.

19. Squires KA, De Paoli AG, Williams C, Dargaville PA. High-frequency oscillatory ventilation with low oscillatory frequency in pulmonary interstitial emphysema. Neonatology 2013;104(4):243-249.

20. Friedlich P, Subramanian N, Sebald M, Noori S, Seri I. Use of high-frequency jet ventilation in neonates with hypoxemia refractory to high-frequency oscillatory ventilation. J Matern Fetal Neonatal Med 2003;13(6):398-402.

21. Khemani RG, Thomas NJ, Venkatachalam V, Scimeme JP, Berutti $\mathrm{T}$, Schneider JB, et al. Comparison of $\mathrm{S}_{\mathrm{pO}_{2}}$ to $\mathrm{P}_{\mathrm{aO}}$ based markers of lung disease severity for children with acute lung injury. Crit Care Med 2012;40(4):1309-1316.

22. Dorling JS, Field DJ, Manktelow B. Neonatal disease severity scoring systems. Arch Dis Child Fetal Neonatal Ed 2005;90(1):F11-F16.

23. Cetinkaya M, Köksal N, Özkan H. A new scoring system for evaluation of multiple organ dysfunction syndrome in premature infants. Am J Crit Care 2012;21(5):328-337.

This article is approved for Continuing Respiratory Care Education credit. For information and to obtain your CRCE

(free to AARC members) visit www.rcjournal.com

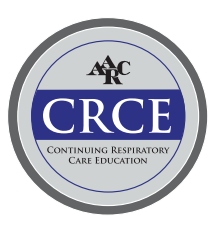

